\title{
UNA APROXIMACIÓN A LA BIOÉTICA DE LA DIVERSIDAD FUNCIONAL DESDE EL DESEO
}

\author{
Antonio Centeno Ortiz \\ antonio.centeno@gmail.com \\ Oficina de Vida Independiente
}

\section{RESUMEN}

Este trabajo expone algunas de las cuestiones que afectan directamente a la forma de comprender y abordar la realidad de las personas cuyo funcionamiento global difiere de los estándares generalmente aceptados como «normales». En la primera parte, se repasan las cuestiones que afectan al uso del lenguaje y su influencia en la representación cultural y simbólica de la discapacidad; a continuación, se exponen las consideraciones sobre la asistencia personal y sexual como base de una vida, efectivamente, independiente. En tercer lugar, se debaten dos cuestiones bioéticas clásicas, el aborto y la eutanasia, su relación con las políticas de la tolerancia y sus implicaciones en la vida de las personas con diversidad funcional. Por último, se exploran alternativas, para pasar de las políticas de la tolerancia a las "políticas del deseo».

Palabras clave: diversidad funcional, discapacidad, políticas del deseo.

AN APPROACH TO THE BIOETHICS

OF FUNCTIONAL DIVERSITY FROM DESIRE

\section{Abstract}

This work exposes some of the issues that directly affect the way of understanding and approaching the reality of people whose global functioning differs from the standards generally accepted as "normal." In the first part, the issues that affect the use of language and its influence on the cultural and symbolic representation of disability are reviewed; The following are the considerations on personal and sexual assistance as the basis of an effectively independent life. Third, two classic bioethical questions are debated, abortion and euthanasia, their relationship with the politics of tolerance and their implications in the lives of people with functional diversity. Finally, alternatives are explored, to move from the politics of tolerance to the "politics of desire."

KeYwORDs: functional diversity, disability, politics of desire. 


\section{LENGUAJE Y REPRESENTACIÓN CULTURAL MÁS ALLÁ DE LA NORMALIDAD}

He comido pan con aceite desde que tengo memoria, conozco bien las diferencias entre usar pan tostado o no, ponerle sal o tomate o ajo o una combinación de todo ello, aprecio los diversos matices de la variedad arbequina, la picual, etc. El pan con aceite es un paisaje sensorial que me acompaña desde la infancia, una realidad construida en lo cotidiano. En cambio, viajes interplanetarios no he hecho ninguno. Aun así, el cine, la televisión y la literatura han poblado mi mente de tantas imágenes e ideas sobre lo que es un viaje espacial que esa idea puede competir con el pan con aceite para hacerse un hueco en mis sueños, en mis pensamientos, en mi realidad. Y así es como construimos «lo real», el mundo se compone de unas entidades que surgen de la experiencia cotidiana y otras que se constituyen desde la cultura y los medios de comunicación.

Para la inmensa mayoría de la gente, la discapacidad es un viaje a Marte, algo de lo que no tienen ninguna experiencia real, cercana. Casi la totalidad de las personas que somos etiquetadas como «discapacitadas» seguimos viviendo en un universo paralelo de escuelas especiales, centros ocupacionales, centros de día, residencias, transporte especial, centros especiales de trabajo, etc., y/o encerradas en casa de mamá, a su cargo y sin apoyos, incluso cuando mamá ya pasa de los 80 . Sin convivencia es más difícil la empatía, y la cultura crea una «realidad de la discapacidad» absolutamente exotizada, alienígena, polarizada al extremo. Sólo se muestra al paria, un tipo desgraciado sin matices y filosuicida, que vende bien porque todo el mundo está encantado de no ser él y de poder mostrarse generoso ayudándole. O bien al gran héroe, capaz de lo inverosímil, una suerte de metamorfosis kafkiana a la inversa que resulta de lo más inspiradora para «los normales». Lo primero justifica la sobreprotección por encima de la libertad personal, como ocurre al encerrarnos en residencias. Lo segundo culpabiliza a la persona con diversidad funcional de su situación: si sufre no es por discriminación, sino porque no se ha esforzado lo suficiente.

En medio de estos extremos, la nada, un desierto ávido de que la cultura, el arte y los medios de comunicación elaboren un relato social mucho más rico y denso, una realidad de textura cercana a la que emerge de lo cotidiano, a la del pan con aceite.

Esta representación cultural de la diversidad funcional, sesgada, estereotipada y polarizada, incorpora también una mirada permanentemente infantilizadora y asexuante. Y claro, si se nos ve como niños se nos trata como tales. Se construye la idea de que ya estamos bien a cargo de las familias, de que esa dependencia es natural. Por eso es necesario sexualizar la diversidad funcional, para repolitizarla. En la medida en que nos visibilicemos como seres sexuados y sexuales, como cuerpos deseantes y deseables, será más difícil seguir pensándonos como niños, y si no somos niños no es natural depender de las familias. Esas situaciones de dependencia son una cuestión política sobre cómo nos organizamos colectivamente para hacer posibles todas las formas de autonomía, incluyendo la que consiste en hacer las tareas cotidianas con las manos de otra persona y nuestras propias decisiones. 


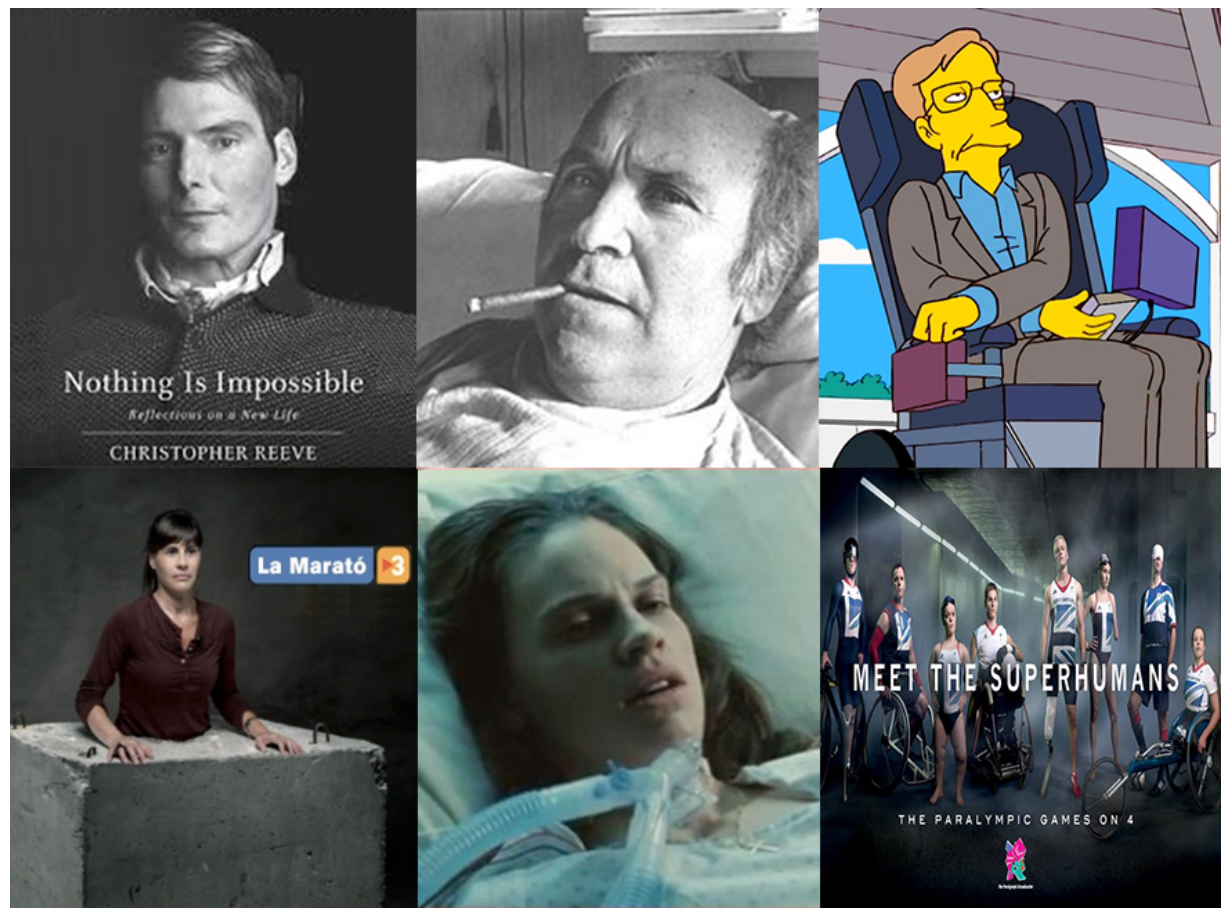

Imagen 1.

Esta forma de autonomía requiere de figuras de apoyo como la asistencia personal (AP) y la asistencia sexual (AS). Enseguida nos ocuparemos de analizar estos apoyos, pero antes de pasar al terreno de lo material conviene revisar dos aspectos clave del imaginario colectivo; el lenguaje y la idea de normalidad.

La construcción de una nueva realidad desde lo simbólico requiere prestar atención al lenguaje, en tanto que este orienta, condiciona e incluso conforma el propio pensamiento. En un ejercicio de realismo, desde el Movimiento de Vida Independiente hace más de una década que decidimos denunciar que el emperador va desnudo, que son falsas las dicotomías normal-anormal (porque todas somos diferentes), capaz-incapaz (porque la capacidad depende del entorno), dependiente-independiente (porque todas recibimos apoyos de y aportamos a la comunidad), y que, derrumbadas estas dicotomías, se revelan infinidad de maneras diferentes de ser, estar y hacer en el mundo. Sin embargo, aquellas que no satisfacen el mandato de productividad competitiva (y de reproducción obligatoria) son castigadas con una discriminación sistemática y sistémica. Por eso, decidimos nombrarnos a nosotras mismas como personas discriminadas por nuestras diferencias funcionales, o más sintéticamente personas con diversidad funcional. No es, pues, un intento de ser políticamente correctos, sino de ser políticos, de abandonar como eje de pensa- 


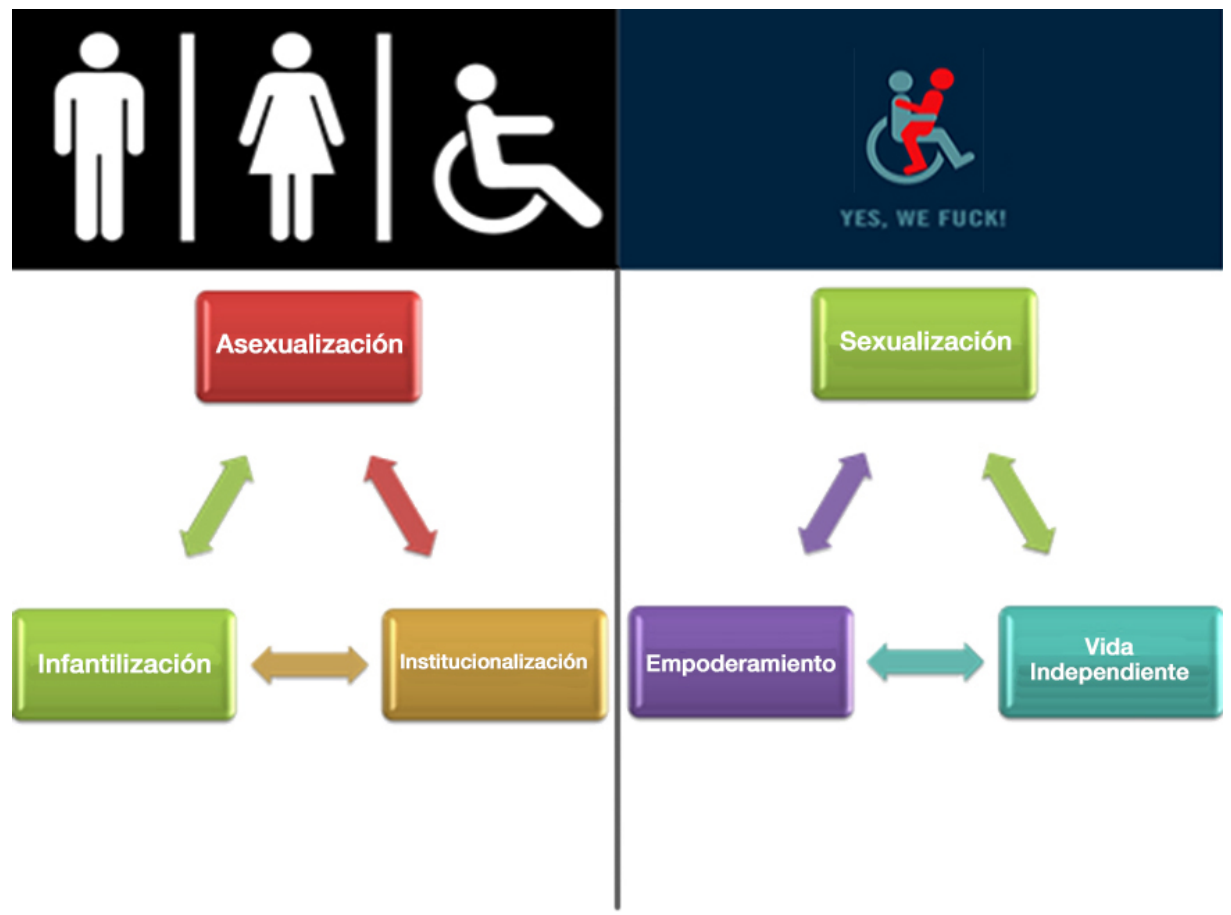

Imagen 2 .

miento las capacidades productivistas de individuos que compiten entre sí, aislados de la comunidad y estigmatizados por sus cuerpos defectuosos, para transitar hacia otro basado en la aceptación, valoración y gestión de las diferencias corporales en un marco de cooperación comunitaria. Es decir, pasar del marco de los infortunios personales al marco de la política.

Quizás, después de leer esto haya quien piense: «Ah, vale, ahora hay que decir diversidad funcional, me parece bien». Habría que ser cuidadosas con este tipo de actitudes, porque no se trata de «lo que hay que decir», sino de «lo que queremos decir». Resulta que la realidad no es algo dado, objetivo, asépticamente observable y describible, sino un constructo de nuestras decisiones personales y colectivas. Por ejemplo, imagine que usted (que seguramente se desplaza caminando) y yo (que lo hago en silla de ruedas) vamos a coger un tren de nuestros amigos de Renfe-Adif y este no tiene rampa sino escalones. Una manera de describir la situación sería: «Antonio no puede subir al tren porque sus piernas no funcionan bien, están mal». Para casi todo el mundo, a simple vista, un hecho obvio, irrefutable. Sin embargo, otra manera de mirar la misma escena podría ser: «A Antonio le impedimos subir al tren porque como comunidad aceptamos que la vía de acceso esté mal hecha». Ahora, y siempre, a usted, y sólo a usted, le toca decidir cuál es la realidad, dónde situamos 


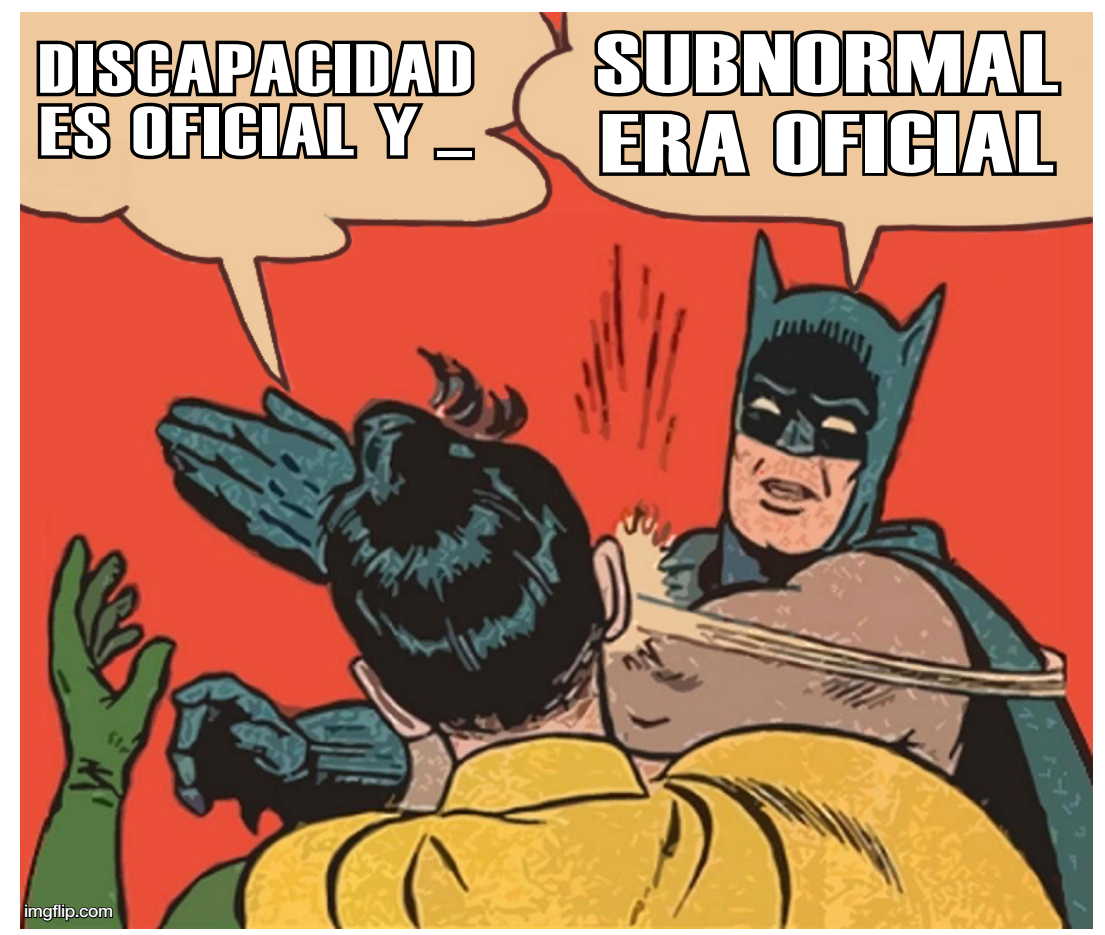

Imagen 3.

el problema y cómo de valiosas y respetables son o no las diferentes maneras de ser, estar y hacer en el mundo. El tejido social que surge de urdir políticamente esos hilos de decisiones personales conforma la realidad colectiva.

Sobre la «normalidad», lo primero que resulta significativo es que quizás sea la palabra más entrecomillada de la historia, probablemente porque responda a la idea más vacía (¿de qué nos informa?), deshabitada (¿quién es normal?), y violenta (sexismo, racismo, capacitismo...) que haya forjado el poder en su anhelo de controlar cuanto pueda amenazarlo. La decimos como sin querer decirla, a medio camino entre la desidia y la culpa por perpetuar estereotipos. Y es en esa dificultad donde merece la pena bucear para encontrar claves que nos permitan, por un lado, comprender cómo opera la idea de normalidad para preservar el poder y, por otro lado, explorar nuevas posibilidades de describir la realidad sin comillas, sin los prejuicios y mitologías que apuntalan dicho poder.

Existe un esquema opresor basado en la idea de normalidad que estructura diferentes formas de discriminación. Viene a ser algo así: 1) el mundo, el espacio de lo posible, se divide en dos únicas categorías excluyentes, esenciales e inmutables: lo normal y lo anormal, 2) se identifican las diferencias y las correspondientes a lo anormal son minusvaloradas, medicalizadas y estigmatizadas, 3) se naturaliza la 


\section{De la discapacidad a la diversidad funcional}

\section{Discapacidad}

- Normalidad

- Autosuficiencia

- Cuerpos defectuosos

Capacidad $\rightarrow$ Ciudadania $\rightarrow$ Dignidad

\section{Diversidad funcional}

- Diversidad

- Interdependencia

- Sociedad excluyente

Dignidad $\rightarrow$ Ciudadania $\rightarrow$ Capacidad

Imagen 4.

desigualdad social a partir de esas diferencias. Así funcionan el sexismo (hombre/ mujer), el capacitismo (capaz/incapaz) o el racismo (blanco/no blanco), por ejemplo.

Es fácil observar que estas dicotomías opresoras son de carácter mitológico, que no se ajustan a la realidad. Al sexismo se le atragantan los movimientos LBGTIQ, que han visibilizado la sexualidad como un continuo fluido mucho más allá de binarismos en la corporalidad, la identidad y la orientación. El capacitismo se tambalea desde que quienes habíamos sido catalogadas como inválidas o discapacitadas nos referimos a nuestra propia realidad como «diversidad funcional», poniendo de relieve que hay muchas maneras de ser, estar y hacer en el mundo y que algunas comportan una discriminación sistemática al interaccionar con un medio social pensado sólo para las maneras de funcionar afines a la idea de productividad. Más claro aún, si cabe, con el racismo, en tanto que la misma idea de "raza» ha sido vaciada de contenido desde los discursos de todas las ciencias y desde la vivencia, cada vez más significativa, de sociedades mestizas, multiculturales y multiétnicas a lo largo y ancho del planeta.

Sin embargo, a pesar de la contundencia de los saberes y las experiencias que certifican lo ineficaz, injusto y cruel que resulta un mundo pensado en términos de normalidad, el poder se resiste a abandonar este esquema opresor. Sigue necesitando que el sexismo garantice la reproducción, que el capacitismo optimice la productividad y que el racismo facilite el expolio internacional. Ante semejante tsunami de normalidad, sólo cabe resistir desde lo cotidiano y desde la cultura, haciendo de la diferencia una trinchera en la convivencia, poniendo en valor la anomalía como potencial creativo. No olvidemos que, como decía Foucault, el poder es un entramado de relaciones, es nuestra responsabilidad hacernos conscientes de los privilegios y las opresiones que nos construyen en relación con las demás para poder tejer vínculos desde la riqueza de la diversidad humana en todos sus aspectos. Pocos ámbitos como el del arte y la cultura para ello, donde siempre ha estado claro que 


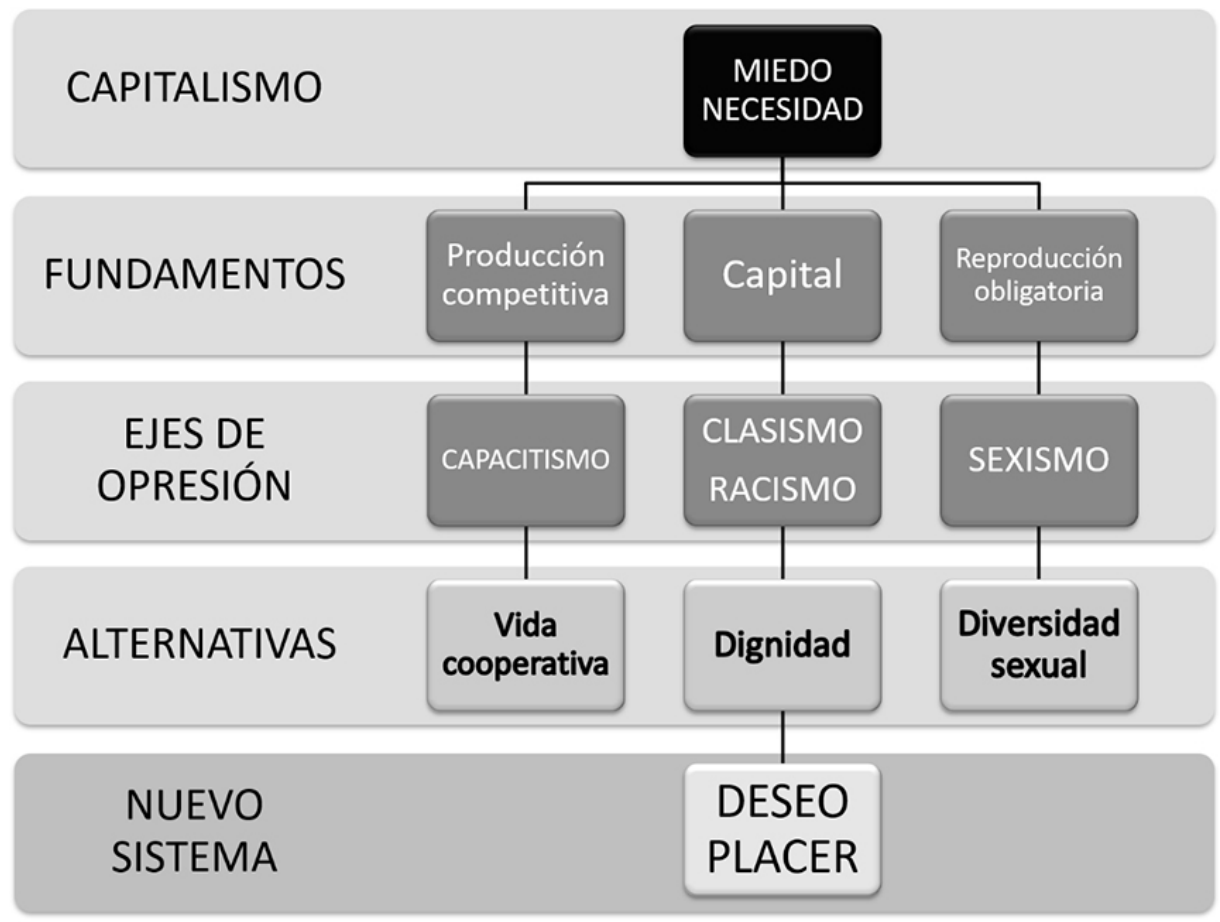

Imagen 5.

la homogeneidad es muerte. Resulta imprescindible, incluso urgente, recuperar el grito político y existencialista del punk: fuck normality!

\section{ASISTENCIA PERSONAL Y ASISTENCIA SEXUAL, LA MATERIALIDAD DE LA VIDA IN(TER)DEPENDIENTE}

Decíamos que la falta de apoyos materiales para la vida diaria, tales como la asistencia personal, la accesibilidad universal o la escuela inclusiva, por ejemplo, mantiene a las personas con diversidad funcional malviviendo en un universo paralelo, confinadas en residencias, escuelas especiales, centros especiales de empleo, centros ocupacionales, etc. Las buenas intenciones, los prejuicios y las inercias sociales nos aíslan y nos convierten en alienígenas para la mayoría de la población, que no tiene ningún tipo de interacción con la diversidad funcional. Esta segregación generalizada genera políticas del «todo sobre nosotras sin nosotras». Se impide la participación política de las personas con diversidad funcional y quienes dicen representarnos carecen de experiencia vital en cualquier aspecto relacionado con nuestra realidad. No es extraño que quieran creer que la de la diversidad funcional es una 
cuestión meramente técnica, pero ¿¿de qué sirve poner rampas en todas las discotecas si cuando entramos nadie quiere bailar con nosotras? Hay que entender que estamos ante una situación de discriminación y opresión generalizadas, poner en valor el lema del Movimiento de Vida Independiente de «Nada sobre nosotras sin nosotras» y, desde ahí, plantear que encerrarnos en instituciones o apoyar a las familias para que dependamos de ellas no es parte de la solución, sino parte del problema.

El capacitismo es caro, lo pagamos fundamentalmente las personas con diversidad funcional, pero la factura también alcanza al resto de la sociedad. Sabemos que incluir la diferencia en cualquier ámbito supone un motor de transformación social que lo mejora para todo el mundo, excluirla implica perder oportunidades para vivir mejor. Son claros ejemplos la escuela, que dispone de más y mejores herramientas pedagógicas para todo el alumnado; el transporte, que resulta más confortable y seguro para cualquiera; o la arquitectura y el urbanismo, que se convierten en más amigables para el conjunto de la población. Siendo grave esta pérdida de oportunidades para un mejor vivir, sobre todo teniendo en cuenta que cada vez viviremos más años y sobreviviremos a más enfermedades y accidentes, hay que señalar que el precio más alto lo pagamos en términos de género. Toda la industria de la discapacidad y la dependencia se sostiene sobre la base de los cuidados obligatorios por parte de las mujeres de la familia. Las vidas de ese ejército de esclavas no tienen valor, las hojas de cálculo de los poderes públicos dicen que ese trabajo es gratis. Cuando entendamos, como decía Machado, que es de necios confundir valor y precio, caeremos en la cuenta de que el capacitismo es insosteniblemente caro.

Es por todo ello por lo que resulta interesante el modelo de vida independiente, porque propone participación y convivencia. «Independencia» es un término histórico, que hace referencia no a hacer las cosas por nosotras mismas, sin apoyos, sino a tener toda la responsabilidad y libertad para gestionar los apoyos necesarios, evitando así las situaciones de dependencia. Es decir, hay un desplazamiento en la toma de decisiones, de la familia y los profesionales a la propia persona con diversidad funcional. Esto supone reconocer la propia autonomía como resultado de la interacción con los demás en iguales condiciones de responsabilidad y libertad, sin relaciones de dominación. En definitiva, estamos hablando de «interdependencia», aunque por razones históricas mantengamos la palabra «independencia». Es desde esta interdependencia desde la que resulta posible tanto la participación directa en la política como la convivencia. Necesitamos recuperar nuestros cuerpos y vidas para nosotras y dejar de ser extraterrestres para las demás.

A menudo, se intenta descalificar el paradigma de vida independiente tachándolo de elitista y económicamente insostenible. Hay que tener en cuenta que asumirse como oprimida y reclamar libertad requiere un empoderamiento que pasa por tener un cierto "passing» como "válidas", algo que casi siempre tiene que ver con privilegios de capacidad, clase, raza, género, etc. Nada nuevo bajo el sol, lo mismo que siempre ha ocurrido en cualquier otro movimiento de liberación. Lo importante es, desde esa conciencia de tener privilegios, articular un proceso político que sea para todas, coherente en la teoría y viable en la práctica. En este sentido, hay que entender que las personas con diversidad intelectual o mental toman sus propias decisiones a su manera, con los apoyos necesarios. Habitualmente, en colaboración con la persona 


\section{TOMIA DE DECISIONES}

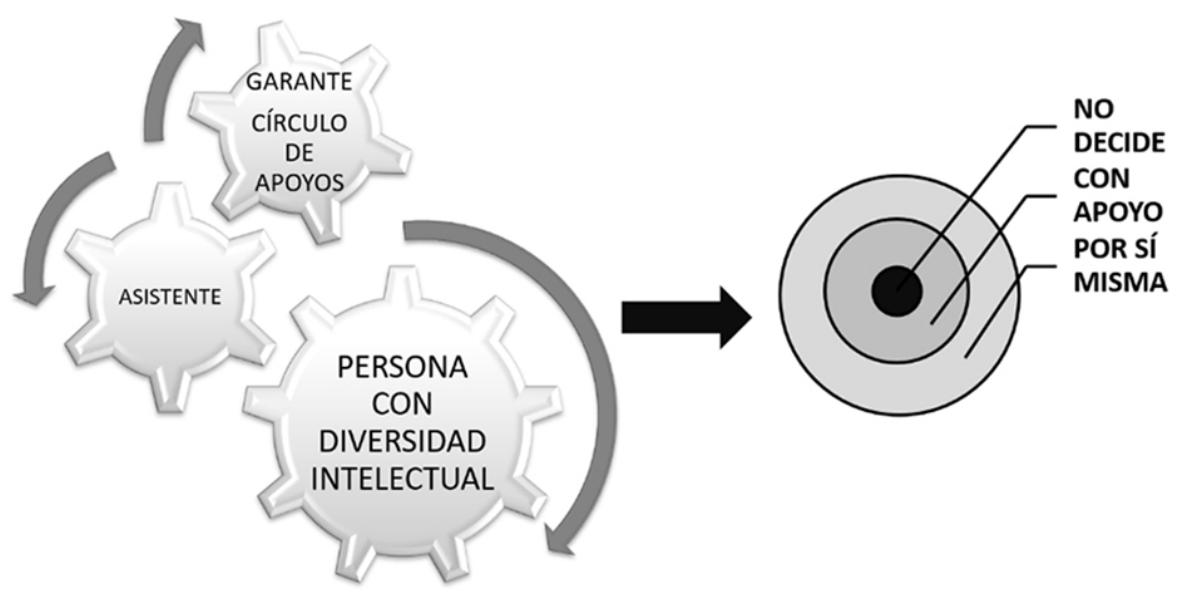

Imagen 6 .

garante y su círculo de apoyos, delimitan un mapa de toma de decisiones; qué pueden decidir por sí mismas, qué deciden con apoyo de sus asistentes y qué deciden mediante la interpretación de su voluntad. Así, cuando hablamos de decidir, queda implícito que nos referimos a que cada cual lo haga a su manera, el modelo de vida independiente también es para las personas con diversidad intelectual o mental.

En cuanto a la cuestión económica, todas las experiencias y estudios señalan que encerrarnos en instituciones es más caro que mantenernos en la comunidad con la asistencia personal necesaria. Algunos datos de los 12 años de experiencia en Barcelona ilustran este hecho general: asistencia personal $2800 € /$ mes de media, plaza residencial $3200 € / \mathrm{mes}$, SROI (Social Return of Investment) 3. Este último significa que por cada euro invertido en asistencia personal se genera un impacto social valorable en 3 euros. No nos encierran para economizar, nos encierran por principios. Y por negocio y corporativismo. A diferencia de los sistemas de salud, educación y pensiones, el sistema de autonomía personal es mayoritariamente privado (concertado o no). Incluso quienes no operan con ánimo de lucro tienen muchas nóminas que sostener, incluida la propia. Esta fue la jugada maestra de los poderes públicos, convertir a quienes reclamaban derechos en gestores de servicios que acaban siendo no un medio, sino un fin en sí mismos.

La falta de apoyos para la autonomía tiene que ver, también, con la idea misma de autonomía y dependencia. Veámoslo con un ejemplo que conozco bien. 
Tengo un certificado oficial que afirma que soy «dependiente en grado III». Para llegar a esa conclusión, un equipo multidisciplinar me hizo preguntas del estilo "¿puede beber por usted mismo?». Contesté que no, porque para beber mi asistente personal coloca el vaso en mis labios y lo inclina. Pero, en rigor, ¿puede alguien contestar afirmativamente? Detrás de ese vaso de agua hay miles de personas sosteniéndolo, se beba con las propias manos o con las del asistente personal; la diferencia entre 10000 manos y 10001 no debería ser significativa. La independencia es una fantasía, una ilusión óptica creada por un sistema social tan complejamente articulado para satisfacer las necesidades cotidianas de quienes funcionan de manera estándar que la tupida malla de productos y servicios que lo hacen posible queda invisibilizada por un uso y costumbre continuado que construye la idea mitológica del individuo autosuficiente. Todas dependemos de todas, todas aportamos a todas, nadie vive "por sí misma», la interdependencia es lo único real, es imposible ser sin las demás.

Lo que debería decir el certificado al que hacía referencia es que sufro una discriminación sistemática y sistémica (de grado x, si quieren) porque no se reconoce mi forma de autonomía, el mundo no está pensado para hacer las cosas a mi manera y esa falta de realismo para asumir la diversidad funcional de las personas es lo que transforma situaciones de interdependencia en dependencia. Mi forma de autonomía consiste en hacer las tareas cotidianas con Otras Manos y Mis Decisiones (OMMD). Por ejemplo, bebo con las manos de mi asistente personal (AP) sosteniendo el vaso y tomando yo todas las decisiones sobre esa acción (qué, cuándo, dónde, cómo, cuánto, etc.) Mi asistente no me da de beber, bebo a mi manera (OMMD). A veces, se ve más claro si el apoyo es tecnológico; cuando paseo lo estoy haciendo con el movimiento de la silla motorizada (ayuda tecnológica, AT) y mis propias decisiones (OMMD), la silla no me pasea. Puede parecer un juego de palabras banal, pero es la diferencia entre ser y vivir como un objeto o como un sujeto, nada menos. Beber con el apoyo de un asistente o pasear con una silla motorizada no son situaciones de dependencia, sino de autonomía OMMD en un entramado de interdependencias que se convierte en dependencia sólo si se me niegan esos apoyos.

El ejemplo de la silla sirve también para entender que «otras manos» es una metáfora que se refiere a cualquier apoyo externo, ya sea otro cuerpo, tecnología, un conjunto de indicaciones o un acompañamiento. Esto es importante para comprender que la OMMD es una forma de autonomía referida a cualquier tipo de diversidad funcional, ya sea física, intelectual o mental. En el caso de las personas con diversidad intelectual esas "manos» a veces son físicas, en otras ocasiones son indicaciones o acompañamiento, o bien todo a la vez. Al hablar de «las propias decisiones» hay que reconocer que existen diferentes maneras de tomarlas. Las personas con diversidad intelectual, con el apoyo de su círculo más cercano, las personas asistentes y la persona garante de que esos vínculos funcionen correctamente, diseñan un mapa dinámico sobre qué deciden por sí mismas, qué con acompañamiento y qué no deciden. Esa es su manera de tomar sus propias decisiones, más compleja que la de la mayoría, pero igual de humana, real y valiosa.

Dando una vuelta de tuerca más a la metáfora de "otras manos", parece claro que si las manos de un asistente personal tocan nuestros cuerpos con intención higiénica no hay ningún tipo de objeción social. Sin embargo, si durante un 


\section{FORMAS DE AUTONOMIÍA}

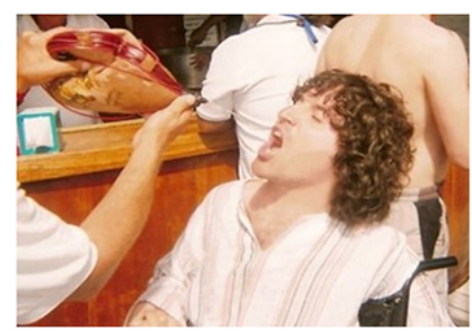

No me dan de beber. Bebo a mi manera, con las manos de mi AP $\mathrm{y}$ mis decisiones
La silla no me pasea. Paseo a mi manera, rodando con AT y mis decisiones
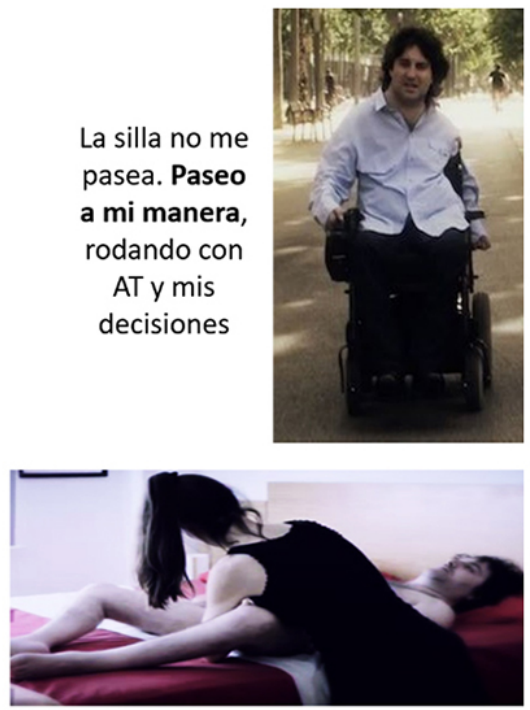

No me exploran ni me masturban. Me exploro y masturbo a mi manera, con las manos de mi AS y mis decisiones

Imagen 7.

solo segundo el objetivo fuese generar placer, entonces se encendería una polémica infinita en la que no poca gente aseguraría que nos precipitamos hacia el Apocalipsis. Es por eso por lo que cuando las tareas a realizar están directamente relacionadas con la sexualidad, la figura de apoyo para la forma de autonomía OMMD es otra, la asistencia sexual (AS). Resulta exactamente igual a la asistencia personal en cuanto a su justificación, su configuración como derecho y los roles que determina. Difiere en las acciones en las que se presta el apoyo, que son la autoexploración y el autoplacer, es decir, en el autoerotismo, que es lo que la mayoría desarrolla con la forma de autonomía mayoritaria (sus propias manos y decisiones). También es un apoyo para acceder sexualmente al cuerpo de otra persona (que no es el asistente). Esto último es habitual cuando dos personas con diversidad funcional necesitan apoyo para alcanzar determinadas posiciones o movimientos en sus prácticas sexuales. Por tanto, se trata de un trabajo sexual (por las tareas a realizar) y de uno de los recursos (como la asistencia personal o la interpretación de lengua signos, p.e.) que requiere la forma de autonomía OMMD para vivir como sujetos y no como objetos. En la misma línea de lo que hace décadas que los feminismos ya nos enseñaron, que sin recuperar el control, la responsabilidad y la libertad sobre nuestros cuerpos y sexualidades nunca recuperaremos nuestras vidas.

Igual que el asistente personal no es alguien con quien compartir tu vida cotidiana, sino que te apoya para que tengas una vida cotidiana propia y puedas 
compartirla con otras personas, el asistente sexual no es alguien con quien tener sexo, sino un apoyo para tener sexo con una misma y con otras personas. Se trata de un apoyo instrumental, ni educativo ni terapéutico, vinculado a una forma de autonomía minoritaria, que ni siquiera es la de todas las personas con diversidad funcional. Y, como todos los trabajos sexuales, tiene su propio marco, determinado fundamentalmente por los roles y prácticas posibles. En particular, no es tarea de la persona asistente excitar ni ser excitada, desnudarse, dar abrazos o besos o mantener prácticas sexuales con la persona asistida. La asistencia sexual es una herramienta clave, en tanto que permite romper la barrera de acceder sexualmente al propio cuerpo, pero no constituye ni la totalidad ni, en general, la parte más importante de nuestra vivencia de la sexualidad. Esta puede ser tan rica, intensa, subyugante, pobre, triste, ridícula o maravillosa como la de cualquiera, sea cual sea su forma de autonomía. Quizás no me crean, casi mejor que no me crean, anímense a comprobarlo por ustedes mismas.

Además del valor de la asistencia sexual como apoyo material concreto, hay que tener en cuenta la dimensión del valor simbólico de esta figura. En este sentido, intentar justificarla con mensajes del tipo «hay personas con diversidad funcional que sólo podrán vivir la sexualidad con estos servicios» valida y refuerza el estereotipo capacitista de la indeseabilidad de los cuerpos diversos y del estigma sobre las personas que hacen trabajo sexual. La asistencia sexual es una herramienta muy importante porque permite romper la barrera de relacionarse sexualmente con el propio cuerpo, de conocerlo y vivirlo también como fuente de placer. A partir de ahí, se hace posible que el vínculo con las demás incluya las dimensiones del deseo y del placer. La indeseabilidad no es exclusiva ni preponderante en ningún grupo humano, pero puede llegar a ser una profecía autocumplida si enseñamos que algunos deseos son inapropiados.

Estos discursos sobre la indeseabilidad de los cuerpos con diversidad funcional sustentan propuestas como la del presidente de Francia, Emmanuel Macron. Parte del lío que ha organizado Macron abriendo un proceso consultivo sobre la legalización de la asistencia sexual ${ }^{1}$ tiene que ver con que bajo el paraguas "asistencia sexual» se está colocando casi cualquier tipo de trabajo sexual que se dirija a las personas con diversidad funcional, y eso genera confusión porque hay propuestas y modelos muy diferentes entre sí. Lo que propone Macron, prácticas sexuales con las personas asistentes, es simple y llanamente prostitución especial y pretende justificarla en base a esa supuesta indeseabilidad. Hay quienes tienen problema con que sea prostitución, y hay quienes tenemos problema con que sea especial (igual que nos pasa con la escuela especial o el transporte especial). Lo que en el Movimiento de Vida Independiente entendemos por «asistencia sexual» no es ni prostitución ni especial, sino un apoyo específico relacionado con nuestra forma de autonomía.

\footnotetext{
${ }^{1}$ Asistencia Sexual (14 de febrero de 2020). Francia estudia legalizar la asistencia sexual. https://asistenciasexual.org/francia-estudia-legalizar-la-asistencia-sexual/.
} 


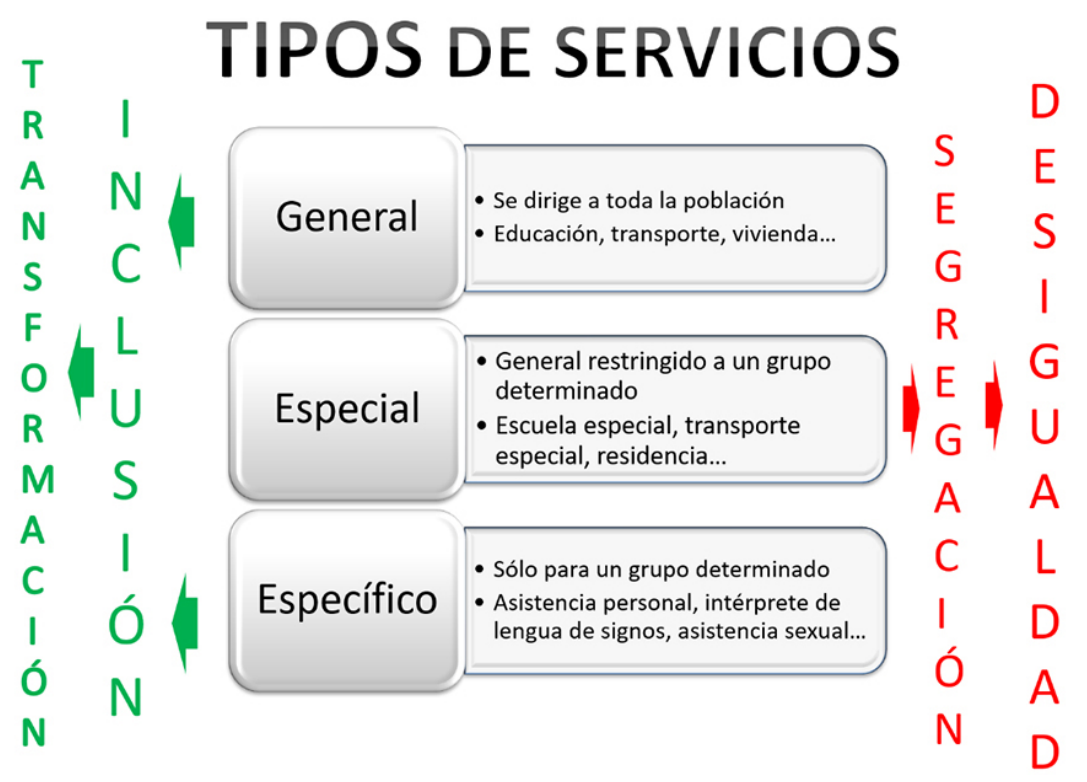

Imagen 8.

Cualquier propuesta sobre cómo debería ser un servicio de asistencia sexual tiene que incorporar lo que hemos aprendido a lo largo de décadas sobre cómo influye la estructura de los servicios sobre los procesos de inclusión y transformación social (ver imagen 8). Cuando un servicio general (es decir, que se dirige a toda la población) atiende a cualquiera, sean cuales sean sus diferencias respecto a lo habitual, el servicio resulta mejor para todo el mundo. Ejemplos claros de esto son el transporte, la educación, la arquitectura o el urbanismo. En cambio, cuando un servicio general en lugar de volverse inclusivo se segrega en un servicio especial para un grupo determinado, no contribuye a la transformación social general y, además, acaba dificultando la convivencia del grupo minoritario con el resto de población. Aquí también son claros los ejemplos ya citados. Por otro lado, también existen los servicios específicos (es decir, que no se dirigen a toda la población, sino sólo a aquellas personas con una determinada forma de autonomía) que se complementan y potencian con los servicios generales inclusivos. Ejemplos de estos servicios específicos son la AP, la AS, los intérpretes de lengua de signos, etc. En este sentido, los modelos de asistencia sexual en los que resulta posible pactar cualquier tipo de práctica sexual deberían encontrar encaje en una prostitución inclusiva, no en una prostitución especial. La propuesta del Movimiento de Vida Independiente se inscribe claramente en la idea de servicio específico.

Para entender las similitudes y diferencias de una figura profesional respecto de otras cercanas, es importante atender tanto a las tareas que se realizan como al rol 


\section{O5 AsistenciaseXuAl.ORG}

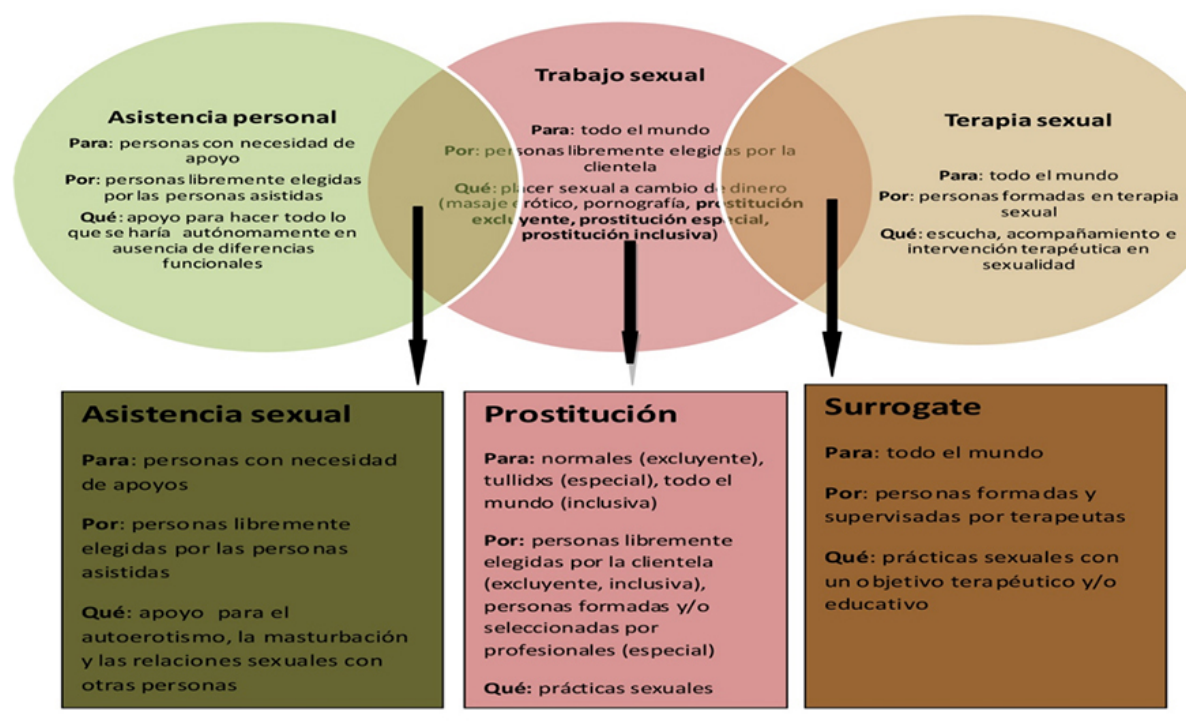

Imagen 9.

que se desarrolla realizándolas. Por ejemplo, aunque la acción sea la misma, resulta muy diferente ponerse un pantalón con un auxiliar de clínica, con un trabajador familiar, con un familiar o con un asistente personal. Mientras que con este último la persona con diversidad funcional se está poniendo el pantalón como un sujeto, a su manera, con sus propias decisiones, en el resto de situaciones es un objeto sobre el que actúa el conocimiento técnico y/o la buena voluntad. La definición de asistencia sexual que proponemos sitúa esta figura exactamente con el mismo rol que la asistencia personal y las tareas propias de los trabajos sexuales. Se trata, pues, de un terreno de intersección que genera una nueva figura. No está de más explicitar que entendemos por trabajo sexual cualquier intercambio libre de placer sexual por dinero. Dentro de esta definición caben multitud de trabajos sexuales, cada uno con su propio marco. No es lo mismo el estriptis que la pornografía, que el masaje erótico o la prostitución. Cada marco determina qué se puede esperar y qué no del servicio, tanto por parte de la persona trabajadora como por parte del cliente, y esto resulta fundamental para su buen funcionamiento. Por tanto, la asistencia sexual es un trabajo sexual con su propio marco, diferente de los otros trabajos sexuales, tal y como ocurre con cada uno de ellos.

En el cuadro (ver imagen 9), necesariamente sintético, pero con los conceptos ya desarrollados en los puntos anteriores, se intenta comprender mejor la AS ponién- 
dola en relación con otras figuras a partir de algunos elementos clave. La necesidad de distinguir cuál es el marco propio de la AS debe situarse en el terreno técnico y pragmático de clarificar las posibilidades y expectativas que ofrece tanto a la persona trabajadora como a la persona con diversidad funcional. Esto, además de ser fundamental para el buen desarrollo y funcionamiento de la figura, nos ayuda a distinguir entre qué constituye un derecho positivo (obligación de los poderes públicos de garantizarlo) y qué un derecho negativo (no se puede prohibir de manera arbitraria). Por otro lado, deberíamos evitar las distinciones basadas en valoraciones morales que muchas veces tienen que ver con los estereotipos sobre la diversidad funcional y con el estigma que pesa sobre los trabajos sexuales y las personas que los realizan.

Reconocer la asistencia sexual como un derecho supone reconocer a muchas personas con diversidad funcional como sujetos interdependientes con su propia forma de autonomía, rescatar esos cuerpos y esas vidas de un papel de objetos en manos expertas y bienintencionadas que nunca deberíamos haber asumido como algo natural, sino como el resultado de una mirada estrecha y triste, incapaz de reconocer el profundo valor humano de la infinidad de maneras de ser y estar en el mundo.

\section{ABORTO Y EUTANASIA, SI NO SON LIBRES NO ES MI REVOLUCIÓN}

Dos cuestiones bioéticas clásicas, el aborto y la eutanasia, ponen de relieve cómo las políticas de la tolerancia esconden un profundo desprecio por la diversidad funcional. En primer lugar, haríamos bien en no confundir la defensa del aborto libre con la defensa del aborto selectivo según las características corporales del feto. La postura más extendida en «ámbitos progresistas» viene a ser algo así como: «No, si yo estoy de acuerdo con el aborto libre, pero mientras no lo conseguimos me parece bien que haya un plazo diferente para malformaciones del feto». Este posicionamiento es, aparte de peligrosamente poco ético, ilegal. Veamos por qué.

Determinar plazos diferentes según alguna característica humana (sexo, etnia, diversidad funcional...) con el argumento de evitar sufrimiento a la futura persona o cargas al entorno familiar atenta contra la dignidad de las personas que ya viven esas realidades (como un servidor aquí o una mujer en la India). Nótese que el objeto de discriminación no es el feto, que no es un ser humano, sino las personas que tienen las características que pretenden justificar el aborto. En el mismo sentido, obsérvese que el sujeto discriminador no es la mujer que aborta, sino el texto legal que establece una minusvaloración de las vidas de las personas que poseen las características en cuestión.

En particular, no puede haber un plazo diferente por «malformación del feto». La Convención sobre los derechos de las personas con discapacidad ${ }^{2}$ forma parte del cuerpo jurídico español, y el Comité de la ONU que vela por su cumpli-

\footnotetext{
${ }^{2}$ https://www.un.org/disabilities/documents/convention/convoptprot-s.pdf.
} 


\begin{tabular}{|c|c|c|c|c|c|c|}
\hline & $\begin{array}{l}\text { Acceso } \\
\text { corporal }\end{array}$ & Vínculo & $\begin{array}{l}\text { Tipo de } \\
\text { servicio }\end{array}$ & $\begin{array}{c}\text { Rol } \\
\text { asistidx }\end{array}$ & $\begin{array}{l}\text { Prácticas } \\
\text { sexuales }\end{array}$ & Asistidxs \\
\hline Asistencia sexual & propio & trabajo & especifico & jefx & masturbación & $\begin{array}{c}\text { necesidad de } \\
\text { apoyos }\end{array}$ \\
\hline $\begin{array}{c}\text { Acompañamiento } \\
\text { erótico }\end{array}$ & acompañante & $\begin{array}{c}\text { voluntariado } \\
?\end{array}$ & especial & $?$ & cualquiera & $\begin{array}{l}\text { diversidad } \\
\text { funcional }\end{array}$ \\
\hline $\begin{array}{c}\text { Prostitución } \\
\text { especial }\end{array}$ & prostitutx & trabajo & especial & clientx & cualquiera & $\begin{array}{l}\text { diversidad } \\
\text { funcional }\end{array}$ \\
\hline $\begin{array}{l}\text { Prostitución } \\
\text { inclusiva }\end{array}$ & prostitutx & trabajo & general & clientx & cualquiera & cualquiera \\
\hline Surrogate & Surrogate & trabajo & general & paciente & cualquiera & cualquiera \\
\hline $\begin{array}{c}\text { Eyaculación } \\
\text { asistida }\end{array}$ & Propio & voluntariado & especifico & paciente & masturbación & $\begin{array}{c}\text { Hombres con } \\
\text { necesidad de } \\
\text { apoyos }\end{array}$ \\
\hline
\end{tabular}

Imagen 10.

miento ya avisó a España ${ }^{3}$ en octubre de 2011 que debía corregir esa diferencia de plazos que se da en la actual ley. Nada dijo el Comité sobre si la corrección debía efectuarse eliminando todos los plazos, o elevando el plazo general a 22 semanas o eliminando el supuesto por "malformación del feto». Algo hay que hacer, pero no necesariamente lo que en su momento proponía el ministro.

Suele argumentarse que debe mantenerse el supuesto por «malformaciones del feto» porque si nace será una carga económica y emocional para la madre. Bueno, es posible, pero parece mejor camino luchar contra las causas sociales que convierten a un ser humano en una carga, en vez de demonizar alguna característica humana. Recordemos que los primeros en ser exterminados por la Alemania nazi ${ }^{4}$ fuimos las personas con diversidad funcional, y que la propaganda utilizada para buscar la aceptación social se basaba, entre otras cosas, en la carga que suponían esos ciudadanos indeseables. Tenemos que encontrar una manera de evitar "cargas insoportables» que no justifique y naturalice las causas sociales que, en muchas ocasiones, subyacen a esa percepción. También es habitual afirmar que debe mante-

${ }^{3}$ https://www.asociacionsolcom.org/files/documentos/Recomendaciones_ONU_Estado_ Espanol_sep_2011.pdf.

${ }^{4}$ http://www.elholocausto.net/parte03/0309.htm. 
nerse el supuesto por «malformaciones del feto» porque si nace sufrirá mucho. Otra vez nos movemos en terrenos pantanosos. Sé que genera rechazo hacer referencia a la propaganda nazi, pero es un hecho histórico que dicha propaganda se imbuía de autoridad científica para referirse a esas realidades como «vidas que no valen la pena ser vividas». No señalo ahí para acusar a nadie de nazi, sería profundamente injusto, sólo digo que la historia debería ser como mínimo una señal de alarma para reflexionar muy fino en estas cuestiones. Y no detecto esa reflexión.

Valga como ejemplo el exitoso artículo de El País «Nadie tiene derecho a obligar al sufrimiento». Después de un párrafo entero invistiéndose de autoridad científica, el autor deja ir una buena ristra de «terroríficas» afirmaciones y algunas inexactitudes. Especialmente significativo para mí es el parágrafo donde describe una de las situaciones de «sufrimiento más allá de lo inimaginable» en términos de "parálisis de ambas piernas. En los casos más graves, que desgraciadamente podrían ser la mayoría si la ley se modificase, el grado de parálisis será completo. Atrofia en estos casos de los músculos de los dos miembros inferiores con grandes deformaciones en los pies, piernas y también en la espalda, con desviaciones muy graves de la columna vertebral. Incontinencia completa de orina y de heces. Impotencia sexual completa». Un servidor, que es feliz como una lombriz, responde casi al milímetro a esa situación.

Así que, cuidado, alármense, pensemos, compartamos experiencias, no todo es como nos lo cuentan. Por otro lado, el artículo también hace referencia a situaciones como «la anencefalia (falta completa de desarrollo de los hemisferios cerebrales)", que sí me parecen claramente sin sentido alguno, tal y como ejemplifica El País en otro artículo sobre el caso de Gloria Muñoz y su hija Alba ${ }^{6}$. Por tanto, no digo que no haya realidades a intentar evitar, digo que no puede hacerse estigmatizando personas a base de naturalizar su presunta infelicidad porque eso ayuda a construir un imaginario colectivo sobre el que se han asentado y se asientan políticas nefastas para la dignidad de todas las personas.

Finalmente, el tercer argumento más popular afirma que debe mantenerse el supuesto por "malformaciones del feto" porque eso hace más libres a las mujeres para decidir sobre su propio cuerpo. La Conferencia Internacional sobre la Población y el Desarrollo (El Cairo, 1994) ${ }^{7}$ y la Cuarta Conferencia Mundial sobre la Mujer (Beijing, 1995) ${ }^{8}$ establecieron el derecho al aborto como un derecho humano en base al derecho a decidir sobre el propio cuerpo y el derecho a la salud. No es necesario

5 Esparza, J. (24 de julio de 2012). «Nadie tiene derecho a obligar al sufrimiento». El País https://elpais.com/sociedad/2012/07/24/actualidad/1343153808_906956.html.

${ }^{6}$ Sahuquillo, M.R. (25 de julio de 2012). «Si me quedase embarazada de otro bebé tan enfermo iría a abortar fuera». El Pais. https://elpais.com/sociedad/2012/07/25/actualidad/1343241210_620587. html.

${ }^{7}$ Naciones Unidas (1995). Informe de la Conferencia Internacional sobre la Población y el Desarrollo https://www.unfpa.org/sites/default/files/event-pdf/icpd_spa_2.pdf.

8 Naciones Unidas (1996). Informe de la Cuarta Conferencia Mundial sobre la Mujer. https:/www.un.org/womenwatch/daw/beijing/pdf/Beijing\%20full\%20report\%20S.pdf. 
(ni aconsejable) ningún otro argumento para defender la libertad total de las mujeres para ejercer su derecho al aborto. La cuestión es, cuando esa libertad total está secuestrada por una legislación como la actual que no respeta los derechos humanos, ¿’hace un «poquito libres» a las mujeres el supuesto de "malformación del feto»?

Parece que la impresión mayoritaria es que sí, y que mejor ese poquito que nada. En mi opinión, es un error gravísimo renunciar a lo establecido por el sistema de derechos humanos a cambio de un pedacito de "pseudolibertad" que consiste en que los médicos tengan la potestad de establecer una valoración suficientemente negativa de ciertas formas de vivir como para despenalizar el aborto. Así, ese pequeño trozo de pseudolibertad se construye validando el poder médico sobre el cuerpo de las mujeres y socavando la dignidad de las personas que ya viven las realidades que el estamento médico decide que no son dignas de ser vividas. ¿Es esta la mejor manera de que las mujeres lleguen a ejercer con total libertad sus derechos humanos? ¿Estamos construyendo libertad cuando acepta mos y reforzamos la medicalización de la vida humana como forma de opresión y dominación sobre quienes no encajen en el modelo utilitarista imperante? A mi modo de ver, la respuesta a ambas preguntas es no.

Si tenemos la conciencia de que algo, como el aborto libre, es un derecho humano no podemos aceptar que se viole dando por buenos cambalaches (como el aborto eugenésico) que validan y perpetúan esa vulneración, menos aún si tomamos conciencia de que ello quebranta también la dignidad de otras personas. Así no se construye libertad, sino situaciones de estigmatización, opresión y dominación de las mujeres y de las personas con diversidad funcional. Deberíamos recuperar la reivindicación del aborto libre como derecho humano vinculado al propio cuerpo y a la salud, y limpiar definitivamente esta lucha de otros argumentos bas$\operatorname{tardos}^{9}$ que lejos de ayudar a la causa la ensombrecen ${ }^{10}$ innecesaria y tétricamente.

En cuanto a la eutanasia, los razonamientos son análogos a los del aborto. Hay un consenso muy amplio respecto a la eutanasia pasiva, entendida como una buena praxis médica basada en el no encarnizamiento terapéutico y el acompañamiento en el proceso de morir, priorizando evitar el sufrimiento incluso cuando ello pueda acortar algo el tiempo de vida clínica. También hay bastante acuerdo social, aunque no tanto como en el caso anterior, en aceptar la eutanasia activa en pacientes aún no terminales pero cercanos a ese estadio, especialmente si han expresado claramente su voluntad al respecto mediante un documento de voluntades anticipadas. Ello permite rechazar tratamientos que podrían alargar considerablemente la vida clínica y recibir los cuidados necesarios para no sufrir dolor mientras las consecuencias del rechazo al tratamiento conducen a la muerte. La cuestión crítica es la eutanasia libre o suicidio asistido. Es decir, cuando la persona que solicita ayuda

9 Regás, R. (30 de julio de 2012). «Siniestra ley del aborto». El Mundo. https://www. elmundo.es/blogs/elmundo/ellas/2012/07/30/siniestra-ley-del-aborto.html.

10 Torres, D. (25 de julio de 2012). «Necesitamos tontos». Público. https://blogs.publico. es/davidtorres/2012/07/25/necesitamos-tontos/. 


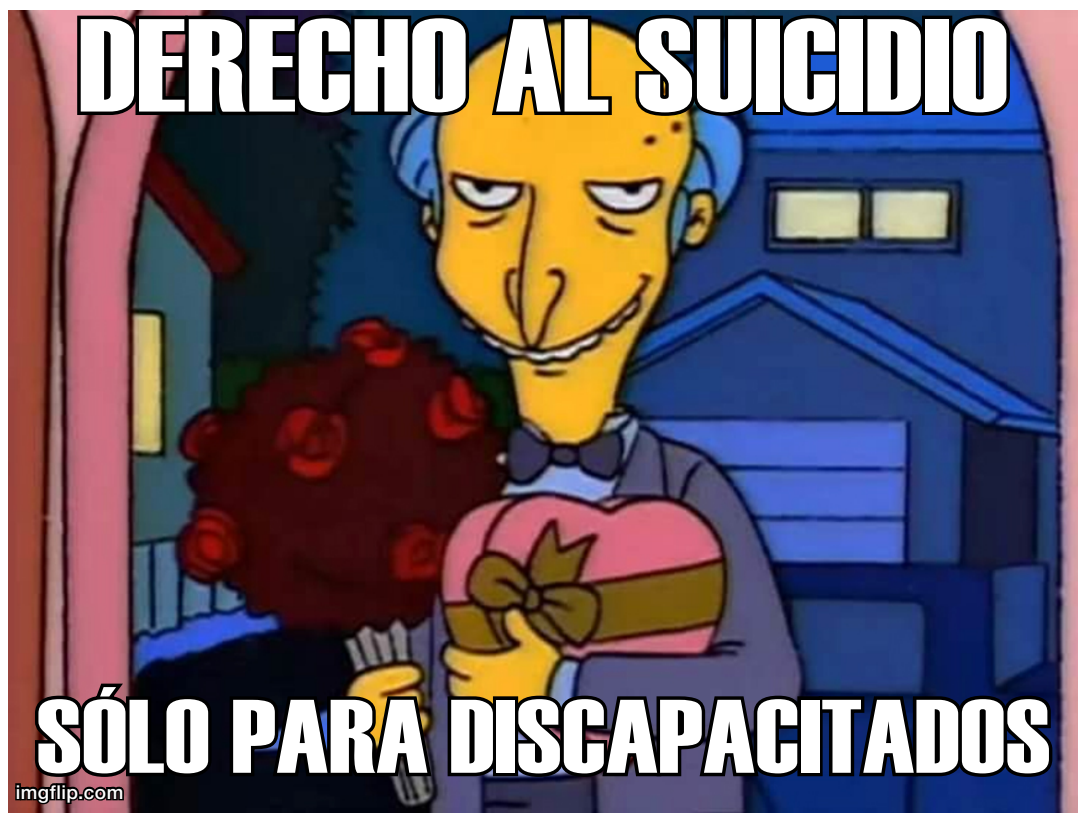

Imagen 11.

para morir como única vía para dejar de sufrir no se encuentra en un estado terminal o cercano a él.

Igual que pasa con el aborto, los problemas comienzan cuando, en lugar de aceptar un suicidio asistido libre, se pretende señalar a algunos grupos humanos como los únicos cuya mala vida permite despenalizar los apoyos necesarios para materializar la voluntad de la persona que los solicita. Un ejemplo paradigmático es el proyecto de ley de eutanasia del actual Gobierno de Espańa. El objetivo de la ley es loable y suscita, o debería suscitar, un consenso amplísimo: evitar el sufrimiento insoportable e irreversible. Lo que resulta inaceptable es que ese texto legal diga que dos (y sólo dos) grupos humanos sufren de manera insoportable e irreversible, a saber, los enfermos terminales y los gravemente discapacitados. ¿¿De verdad que ninguna persona sin discapacidad ni enfermedad terminal puede sufrir de manera insoportable e irreversible? Por supuesto que sí, sabemos que eso ocurre, luego la intención, o como mínimo el efecto, de semejante ley no sería acabar con dicho sufrimiento, sino señalar a los enfermos terminales y los gravemente discapacitados como únicos titulares de esa condición y, eventualmente, acabar con nosotras si damos consentimiento. Esta es la política de la tolerancia, no se nos obliga a morir, claro, pero se nos abre la puerta de salida exclusiva para nosotras. El resto de vidas son demasiado valiosas, son vidas no sólo toleradas, sino valoradas, celebradas, deseadas.

Por supuesto, cuando hablamos de suicidio asistido libre somos conscientes de que habrá que establecer mecanismos y protocolos que permitan asegurarse de 
que la persona conoce y dispone de todas las opciones que podrían revertir o hacer soportable su sufrimiento. Sería conveniente que la manera de acreditar el sufrimiento no estuviese sólo en manos del estamento médico, ni de ningún otro. El sufrimiento humano no es reductible a la mirada biomédica; filósofas, artistas, poetas o cómicas, por ejemplo, pueden penetrar en ese campo de conocimiento hasta lugares inaccesibles para la medicina. También habría que poner atención a que las herramientas de seguridad y acompańamiento necesarias no se conviertan en un tutelaje o una carrera de obstáculos insuperable. Finalmente, para cerrar la analogía con el aborto, nótese que quien discrimina no es la persona que decide suicidarse por tener ciertas características, sino el texto legal que informa de que esas formas de vida son tolerables, pero menos protegibles, menos valiosas que el resto.

\section{MÁS ALLÁ DE LA TOLERANCIA, POLÍTICAS DEL DESEO}

Vistas las nefastas consecuencias de las políticas de la tolerancia, necesitamos explorar posibilidades como, lo que podríamos denominar políticas del deseo. Para ilustrar la propuesta, recordemos que es habitual asistir al debate sobre si la asistencia sexual es un derecho o no. Quienes están en contra argumentan, entre otras cosas, que no es un derecho porque no responde a una necesidad. Se puede vivir sin placer sexual, dicen. Resulta una concepción del derecho como mínimo inquietante. Mi padre, que nació pobre en pleno fascismo, no fue nunca a la escuela. Así que sí, se puede vivir sin educación, pero ¿queremos vivir sin educación? Esta me parece la cuestión clave, hacer política desde el ¿qué necesito? o hacerla desde el ¿qué quiero? La política de la necesidad responde al miedo, en tanto que no se puede vivir sin tal cosa, y desresponsabiliza, ya que se presenta la necesidad como una ley natural externa a la persona. Por supuesto, el miedo puede ser encauzado socialmente y llegamos a ser tolerantes con lo innecesario, pero siempre será tratado como algo de menos valor, en ningún caso algo deseable. Quizás sea hora de activar la política del deseo, ¿qué quiero?, como una vía para la responsabilización y el compromiso personal y social.

Este hacer política desde el deseo requiere un compromiso ético en torno al propio deseo. En primer lugar, hay que asegurarse de que nuestros deseos sean nuestros. ¿Queremos que el centro de nuestras vidas sea acumular capital o queremos vivir con dignidad? Ninguna ley escrita nos obliga a ser productivas competitivamente contra las demás, ni tampoco a reproducirnos obligatoriamente. Pero lo hacemos, en primer lugar, por una falta de herramientas sociales alternativas a ese modo de vida, pero también porque lo deseamos, porque hemos aprendido que así son las buenas vidas, las vidas deseables. Resulta imprescindible construir una erótica de la dignidad, situarla en el centro de cualquier deseo que construyamos. Por otro lado, conviene cuestionarnos nuestra vivencia del deseo. A veces, pudiera parecer que el único sentido del deseo es convertirse en placer, aplicando en cada caso una serie de técnicas. Este sería un deseo muerto, repetitivo, incapaz de mover todo lo necesario para afrontar la complejidad de vivir. Necesitamos que sentir deseo sea 
una forma de placer, de manera que los segmentos inconexos que sitúan deseo y placer en sus extremos se conviertan en círculos virtuosos en los que deseo y placer se retroalimentan, se mantienen tan vivos como todo aquello a lo que tienen que dar respuesta.

Finalmente, necesitamos saber quiénes somos, con quién contamos para abrir experiencias en estas políticas del placer. De entrada, somos muchas las que compartimos la experiencia vital de haber sido machacadas por las políticas del miedo y su mitología normalizadora. Las mujeres, la comunidad LGBTQ+, las gordas, las locas, las racializadas, las personas con diversidad funcional, etc. Y quienes han vivido la breve ensoñación de la normalidad despertarán bruscamente cuando la edad, la enfermedad u otras circunstancias les expulsen de ese paraíso de plástico. Así que la alianza está abierta a cualquiera. Nuestras diferencias han sido patologizadas, estigmatizadas y parece que, como destino final, se nos reservan algunos huecos sociales en los que tolerarnos. Pocas cosas tan generadoras de un odio soterrado y camaleónico como esa tolerancia buenista. Sabemos que nada, salvo el deseo, es suficiente. Todo lo que no sea desearnos es asimilacionismo y abandono. Estamos aquí para transformar, lo queremos todo, exigimos deseo. 
